\title{
Angiograhic profile and in-hospital outcome of young patients presenting with ST Elevation Myocardial Infarction (STEMI) in tertiary cardiac hospital
}

\author{
Rabindra Pandey, "Arun Maskey, Bishal Shrestha, Arjun Budhathoki, Sabindra Bhupal Malla, \\ Bibek Baniya, Surendra Bhatta, Sashit Shrestha, Praveen kumar Yadav \\ Department of Cardiology, Shahid Gangalal National Heart center, Bansbari, Kathmandu Nepal
}

Keywords: Young, myocardial infarction, Angiographic profile, Primary percutaneous coronary intervention, STelevation myocardial infarction, In-hospital outcome.

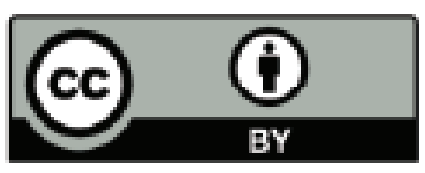

This work is licensed under a Creative Commons Attribution 4.0 Unported License.

\section{Introduction}

Coronary artery disease is common and Acute Myocardial Infarction (AMI) accounts for a large proportion of premature death worldwide. ${ }^{1}$ The death rates have been declining in the west but these are increasing in developing countries, more so in south asian countries. ${ }^{2}$ The continuous rise in Prevalence of Central obesity, diabetes, hypertension and dyslipidemia in addition to physical inactivity, over indulgence in high calorie/ less fiber diet pattern, cultural preferences, and sub-optimal heath care have been incriminated. ${ }^{3}$ Although traditional risk factors explain most of CAD, $15 \%-20 \%$ have no identifiable risk factors. ${ }^{4}$ CAD is relatively less common in young age group. It is reported to be in between $5-10 \%$ in subjects below 40 years of age. ${ }^{5}$ approximately $10-12 \%$ of all ST Elevation Myocardial Infarction (STEMI) patients are younger than 45 years old. ${ }^{6}$

\begin{abstract}
Objective: To assess the angiographic profile and in hospital outcomes of primary percutaneous coronary intervention among young patients presenting with acute ST Elevation Myocardial Infarction and underwent primary PCI.

Methods: The retrospective observational study was conducted at Shahid Gangalal National Heart Centre (SGNHC), Kathmandu, from july 2020 to June 2021, and included acute ST-Elevation Myocardial Infarction patients underwent primary percutaneous coronary intervention (PCI). Data was collected on demographic, angiographic, and in-hospital outcomes. Patients $<45$ years were considered young. Data was analysed using SPSS 21.

Results: Total 104 patients met the inclusion criteria. Mean age of presentation was $40.16+-4.42$ years. Over threefourth of the patients were male 80 (76.9\%). Smoking was the most prevalent risk factor with $61(58.6 \%)$ patients followed by hypertension 35 (33.6\%) and dyslipidemia 23 (22.1\%). Single Vessel Disease (SVD) was the most common finding seen in 62 patients (59.6\%) and Left Anterior Descending Artery (LAD) was the most commonly involved artery seen in approximately three fourth patients 80 (76.9\%) followed by RCA $61(58.6 \%)$ and LCX 15(14.4\%). Left Main Coronary Artery is involved in 3 patients(2.9\%). $6(5.8 \%)$ patients suffered from cardiogenic shock either at admission or during hospital stay. Total In hospital mortality was seen in $3(2.9 \%)$ patients.

Conclusions: Among young patients ( $<45$ years old) with STEMI who underwent PPCI in underdeveloped country majority are males and smoking is the most prevalent risk factor. Single vessel disease and LAD involvement is the most common angiographic finding and they have favorable in-hospital outcome.
\end{abstract}

\section{*Corresponding Author:}

Prof. Arun Maskey

Department of cardiology

Shahid Gangalal National Heart center, Bansbari,Kathmandu Nepal.

Email: maskeyarun@yahoo.com 
The short term prognosis and functional status is better in younger individual as compared to the elderly counterpart. ${ }^{7}$ The angiographic profile is different in younger patients with Myocardial Infarction (MI) than elderly such as less severe and less extensive disease without much calcification and systemic comorbidity. ${ }^{8}$

There is enormous data available regarding MI in general population but data pertaining to young patients is scarce globally and particularly in Nepal. The objective of this study was to evaluate the angiographic characteristics and in-hospital outcome of young patients below 45 years age presented with ACS who underwent primary PCI.

\section{Materials and Method}

104 patients less than 45 years of age who presented to Shahid Gangalal National Heart Centre (SGNHC) with acute ST elevation myocardial infarction (STEMI) as defined according to fourth universal definitions and underwent primary Percutaneous Coronary Intervention (PPCI) from july 2020 to june 2021 were included in this study. None of these patients had any previous history of diagnosed CAD. Patients with concomitant severe valvular heart disease or cardiomyopathy were not included. Severe renal impairment and hepatic impairment were also excluded.

All these patients were taken up for primary PCI. Selective coronary angiography in multiple $(\geq 2)$ views was performed by standard technique to define both the extent and severity of disease. Significant CAD was defined as at least $70 \%$ reduction in the diameter of major epicardial coronary arteries i.e. left anterior descending (LAD), left circumflex ( $\mathrm{LCx}$ ) or right coronary artery (RCA) and their branches; or at least 50\% luminal narrowing of the left main coronary artery (LMCA). Patients were classified as having single-vessel disease (SVD), double-vessel disease (DVD) or triple vessel disease (TVD) accordingly. Presence of significant CAD in LMCA was classified as DVD.

They were also studied for the presence of conventional risk factors such as presence of diabetes, hypertension, obesity, smoking, dyslipidemia and family history of premature CAD. All cases were followed until discharge or death and major clinical outcomes like NYHA 3-4 heart failure, cardiogenic shock, high degree AV block were noted.

Data were entered into spread sheet ( Microsoft Excel) and analysed using Statistical Package for the Social Science (SPSS) software.

\begin{tabular}{|l|c|c|}
\hline \multicolumn{3}{|c|}{$\begin{array}{l}\text { Table 1: prevalence of risk factors in Young patients <45 years } \\
\text { with STEMI undergoing PPCI (n=104) }\end{array}$} \\
\hline & Yes & No \\
\hline Smoking & $61(58.6 \%)$ & $43(41.4 \%)$ \\
\hline Hypertension & $35(33.6 \%)$ & $69(66.4 \%)$ \\
\hline Diabetes mellitus & $17(16.3 \%)$ & $87(83.7 \%)$ \\
\hline Dyslipidemia & $23(22.1 \%)$ & $81(77.9 \%)$ \\
\hline $\begin{array}{l}\text { Family history of } \\
\text { premature CAD }\end{array}$ & $3(2.9 \%)$ & $101(97.1 \%)$ \\
\hline
\end{tabular}

The results were reported as mean \pm standard deviation for the quantitative variables and percentages for the categorical variables. Clinical presentation factors was demonstrated in tabular form using frequencies and percentage.

\section{Results}

Among 104 patients majority were male 80 (76.9\%) and 24 (23.1 $\%)$ were female. The mean age for male was 41.03 years and for female was 36.93 years. 6 patients (5.8\%) were below 30 years old, youngest being 25 years old. Among the young patients who underwent primary PCI smoking was the most common coronary risk factor present in $61(58.6 \%)$ patients. This was followed by hypertension in 35 (33.6\%), dyslipidemia 23 $(22.1 \%)$ and diabetes $17(16.3 \%)$. Family history of premature CAD was present in $3(2.9 \%)$ patients as shown in Table 1.

On analyzing data from Coronary angiogram reports, Single Vessel Disease (SVD) was the most common finding 62(59.6\%). Multi Vessel Disease (DVD +TVD) was less common comprising of $42(40.4 \%$ ) (Figure1).

\section{Coronary angiography findings}

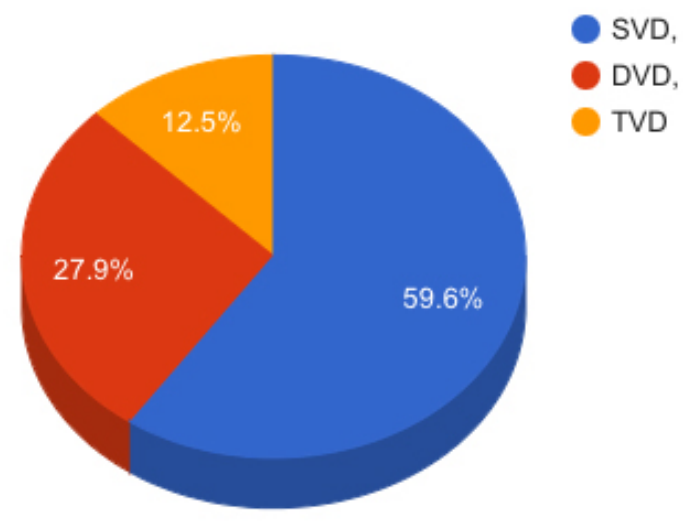

Figure 1.Coronary angiogram findings.

Among the coronary artery, Left Anterior Descending (LAD) was the most common artery to be obstructed seen in in 80(76.2\%). It was involved in all patterns of CAD, whether SVD, DVD or TVD. Second most common artery to be affected was RCA which was involved in 61(58.6\%) patients. LCX was involved in $15(14.4 \%)$ patients. Left main artery was the least involved ;3 (2.9\%) patients (Figure 2).

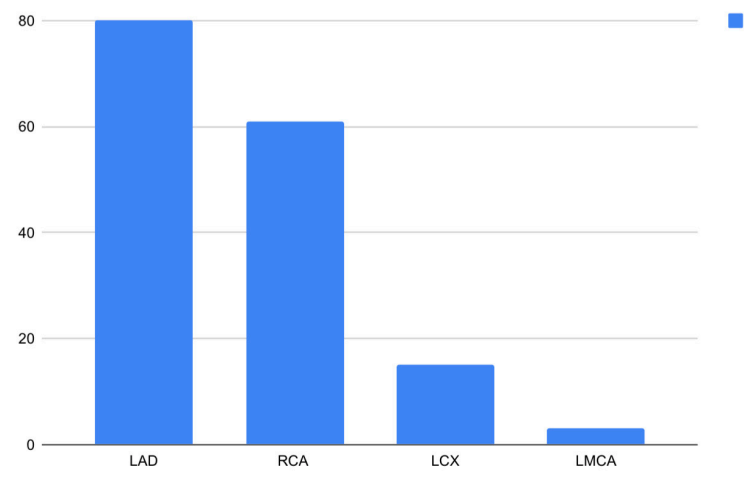

Figure2: Involvement of coronary artery 


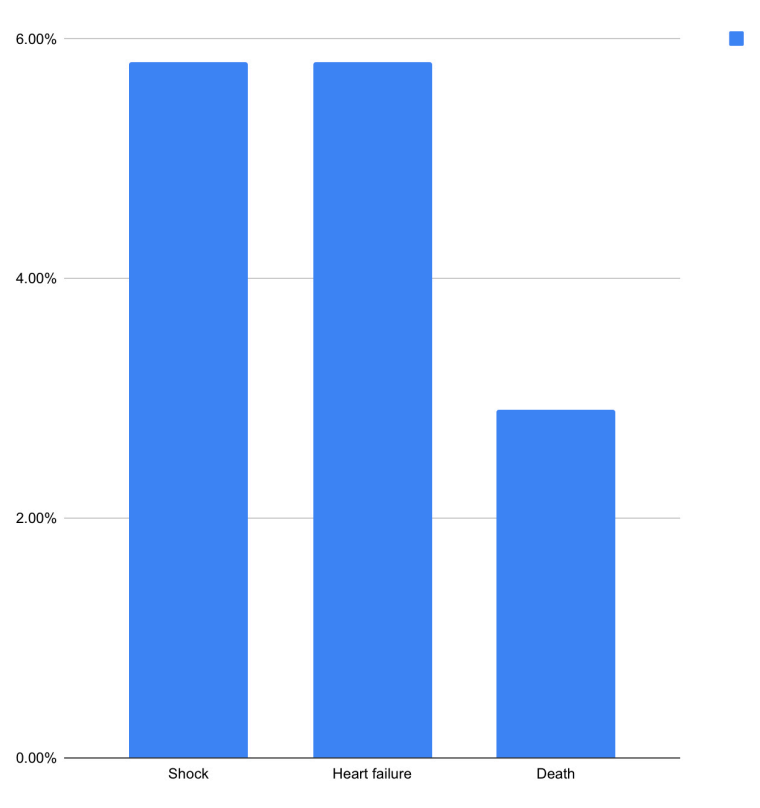

Figure 3: inhospital outcome

Out of 104 patients who underwent PPCI, 6 (5.8\%) had suffered cardiogenic shock, 6 (5.8\%) had developed NYHA 3-4 heart failure. None of the patient developed Complete heart block. Most of the patients 101 (97.1\%) improved and were discharged without significant morbidity.However 3 patients $(2.9 \%)$ died in hospital and all of these 3 had TVD along with significant obstruction in left main coronary artery. (Figure 3)

\section{Discussion}

The current study was an effort to understand the angiographic characteristics and the outcomes of primary $\mathrm{PCI}$ in young patients presenting with STEMI. In this retrospective observational study of 104 young patients below 45 years of age who presented with STEMI and underwent primary PCI in SGNHC, Mean age of patients was 40.16 years with male preponderance which was similar to the findings conducted by Andrade et al. ${ }^{9} \quad \mathrm{MI}$ in young patients have some important clinical angiographic and prognostic differences as compared to that in older patients. ${ }^{10}$ Even though young MI form small proportion of total AMI cases; it is an important group to examine for the purpose of risk factor modification and secondary prevention. 1 year registry of STEMI from 2018 from a high volume tertiary centre in Nepal showed that $11.8 \%$ of all STEMI patients were young $(<45$ years old). As expected, there is male predominance. This skewed gender distribution of the study population can be attributed to the gender bias and atypical presentation which was also seen in south asian cohort of INTERHEART study. ${ }^{11}$

As seen in the Study by Tamrakar et $\mathrm{al}^{12}$ We found that smoking is the most common modifiable risk factor among young AMI patients. The predominance of single vessel disease in these young patients matches with similar findings from various other studies which ranges from $39-80 \% .^{13-16}$ As per different studies The involvement of LAD is seen in around $40-68 \%$ young patients with MI making it the most common artery involved in MI of young patients. ${ }^{9,17-19}$ However in a subgroup analysis of a study by Manjil et al. Who studied angiographic profile of 200 patients of all age group Undergoing PCI, they have found that among young patients there is similar involvement of LAD with RCA $40 \%$ each among those undergoing PCI. ${ }^{15}$ In a study done by Sahi et al. From 2018-2019 among young ( $<45$ years old) patients admitted in nearby hospital in Kathmandu for the first episode of Acute Coronary Syndrome (ACS); LAD was involved in $60 \%$ of cases and SVD was seen in majority (72\%) of STEMI. ${ }^{17}$

In another study from India undergoing CAG for either stable angina or CSA, SVD (65\%) was the most common finding in CAG followed by normal/recanalised coronaries. LAD was the most common vessel involved (68\%), followed by LCX (25\%) and RCA $(19 \%){ }^{18}$

An analysis of PCI (largely elective) cohort registry of Malaysia from 2007-2009, young patients ( $<45$ years male, $<55$ years female) constituted $15.5 \%$ of total patients who underwent PCI, and among them, 54\% had SVD, $0.8 \%$ had LMCA disease.

As in various other studies, which have showed in-hospital mortality rate of the approximately $0 \%$ to $3 \%$ among young MI, our study also showed the lower mortality rate of $2.9 \%$, which ranges between $5-10 \%$ in different series. ${ }^{19-21}$ The inhospital mortality rate observed in overall (both young and old combined) population who present with STEMI was found to be $6.2 \%$ in SGNHC STEMI registry which was most commonly due to cardiogenic shock and cardiac free wall ruture. Similarly a study done in 2008 from India showed 30 day mortality of 8.6\% for STEMI patients. It had enrolled 12495 STEMI patients. The high rate of mortality was mainly attributed to delayed presentation to hospital. ${ }^{22}$

In an overview The overall incidence of cardiogenic shock in patients $>40$ years with STEMI was found to be $7.9 \%$ The proportion of STEMI patients developing cardiogenic shock was increasing from $6.5 \%$ in 2003 to $10.1 \%$ in $2010 . .^{23}$ In our study the incidence of cardiogenic shock is lower $(5.8 \%)$ than this as expected.

\section{Limitations of the study:}

This study has certain limitations. First it is an observational study done in only one centre so certain confounding variables could have played role. We only analyzed the patients who reached the hospital and underwent primary PCI, so it might not be a true representative of the general population. Myocardial Infarction with Normal Coronary Arteries (MINOCA) represents an important subgroup in young patients, all of our patients had obstructive culprit vessels, probably because we included only those patients who underwent primary PCI. The clinical outcome analysed was only in hospital death due to any cause, it has not elaborated about re-infarction, stroke, stent thrombosis or bleeding or cause of death.

\section{Conclusion}

Though the frequency of young acute STEMI is small, but these patients have different clinical and laboratory characteristics and early clinical outcomes vs. older patients. It is more likely associated with single vessel disease. The LAD and hence anterior wall is the most commonly involved. smoking is most common modifiable risk factor.Furthermore emphasis should also be given to the contributing factors like homocysteine, fibrinogen, hsCRP, apo B, apo A1, Lp(a), SCAD etc. in all young patients with established CAD without conventional risk factors. With early diagnosis and treatment; younger patients have favorable short term prognosis than elderly, yet the psychological and economic burden to patient, their family and whole society is substantial. it is therefore important to formulate preventive and management strategies to decrease the burden of the disease. 


\section{References}

1. Dugani SB, Ayala Melendez AP, Reka R, Hydoub YM, McCafferty SN, Murad MH, et al. Risk factors associated with premature myocardial infarction: a systematic review protocol. BMJ. 2019 Feb; 9(2):e023647. DOI PubMed Google Scholar

2. Joshi P, Islam S and Pais P. Risk Factors for Early Myocardial Infarction in South Asians Compared With Individuals in Other Countries. JAMA. 2007; 297(3):286-294. https://doi. org/10.1001/jama.297.3.286

3. Deedwania P, Singh V. Coronary artery disease in South Asians: evolving strategies for treatment and prevention. Indian Heart J. 2005 Nov-Dec;57(6):617-31. PMID: 16521627.

4. Smith SC. Current and future directions of cardio-vascular risk prediction. The American journal of cardiology. 2006 Jan;97(2A):28A-32A. DOIPubMedGoogle Scholar

5. Aggarwal, A., Srivastava, S., \& Velmurugan, M. (2016). Newer perspectives of coronary artery disease in young. World journal of cardiology, 8(12), 728-734. https://doi. org/10.4330/wjc.v8.i12.728

6. Adhikari CM, Acharya KP, Manandhar R, Sherpa K, Tamrakar R, Bogati A, et al. Shahid Gangalal National Heart CentreST-elevation Myocardial infarction Registry(SGNHCSTEMI-Registry), Nepal. Nepalese Heart Journal. 2020;17(1):7-16. DOI

7. Egred M, Viswanathan G and Davis GK. Myocardial infarction in young adults. Post grad Med J. 2005; 81(962):741-745. https://doi.org/10.1136/pgmj.2004.027532

8. Hsu JT, Kyo E, Chu CM, Tsuji T, Watanabe S. Impact of calcification length ratio on the intervention for chronic total occlusions. Int J Cardiol. 2011;150(2):135-141.

9. Pedro Beraldo de Andrade, Fábio Salerno Rinaldi, Igor Ribeiro de Castro Bienert, et al., Clinical and angiographic profile of young patients undergoing primary percutaneous coronary intervention, Revista Brasileira de Cardiologia Invasiva, Vol. 23 (2), 2015, pp. 91-95, ISSN 2214-1235, https://doi. org/10.1016/j.rbciev.2015.12.005.

10. Rathod KS, Jones DA, Gallagher S, Rathod VS, Weerackody $\mathrm{R}$, Jain AK, et al. Atypical risk factor profile and excellent long-term outcomes of young patients treated with primary percutaneous coronary intervention for ST-elevation myocardial infarction. Eur Heart J Acute Cardiovasc Care 2016; 5: 23-32.

11. Yusuf S, Hawken S, Ounpuu S, Dans T, Avezum A, Lanas $\mathrm{F}$, et al; INTERHEART Study Investigators. Effect of potentially modifiable risk factors associated with myocardial infarction in 52 countries (the INTERHEART study): Case-control study. Lancet 2004;364: 937-952

12. Tamrakar R, Bhatt YD, Kansakar S, Bhattarai M, Shaha KB and Tuladhar E. Acute myocardial infarction in young adults: study of risk factors, angiographic features and clinical outcome. Nepalese Heart Journal. 2013; 10(1):1216. https://doi.org/10.3126/njh.v10i1.9740

13. Adhikari CM, Rajbhandari R, Limbu YR, Malla R, Sharma R, Rauniyar B, et al. A study on major cardiovascular risk factors in Acute Coronary Syndrome (ACS) patient 40 years and below admitted in CCU of Shahid Gangalal National Heart Center. Nepalese Heart Journal. 2010; 7(1):20-24. https://doi.org/10.3126/njh.v7i1.8497
14. Rauniyar, B. K., Kadel, A., Acharya, K. P., Thakur, K. K., Adhikari, R. B., Limbu, D., Rajbhandari, S., Kansakar, S., Adhikari, C. M., Maskey, A., Rajbhandari, R., \& Malla, R. (2020). Angiographic profile of young patients ( $\leq 40$ years) in a tertiary care center of Nepal. Asian Journal of Medical Sciences, 11(6), 68-71. https://doi.org/10.3126/ajms. v11i6.30163

15. Manzil AS, Radhakrishnan V, Rajan JS. Clinical Outcomes and Risk Factor in Patients with STEMI Treated with Percutaneous Coronary Intervention. Int J Clin Med 2015; 6: 753-8.

16. Konishi H, Miyauchi K, Kasai T, Tsuboi S, Ogita M, Naito $\mathrm{R}$, et al. Long-term prognosis and clinical characteristics of young adults (? 40 years old) who underwent percutaneous coronary intervention. J Cardiol 2014; 64: 171-4.

17. Sahi R, Shah R, Gajurel RM, Khanal RR, Poudel CM, et al. (2020) Cardiovascular risk factors and clinical pattern in young Nepalese population with acute coronary syndrome presenting to a tertiary care center of Nepal. J Cardiovasc Med Cardiol 7(3): 235-241. DOI: 10.17352/24552976.000145

18. Prakash, B., Jaiswal, A., \& Shah, M. M. (2020). Demographic \& angiographic profile of young patients aged 40 year \& less undergoing coronary angiography in a tier II city of Eastern India. Journal of family medicine and primary care, 9(10), 5183-5187. https://doi.org/10.4103/jfmpc. jfmpc_1063_20

19. Zuhdi AS, Mariapun J, Mohd Hairi NN, Wan Ahmad WA, Abidin IZ, Undok AW, Ismail MD, Sim KH. Young coronary artery disease in patients undergoing percutaneous coronary intervention. Ann Saudi Med. 2013 Nov-Dec;33(6):572-8. doi: 10.5144/0256-4947.2013.572. PMID: 24413861; PMCID: PMC6074922.

20 Feijó, I.P., Schmidt, M.M., David, R.B., Martins, J., Schmidt, K., Gottschall, C., \& Quadros, A.S. (2015). Clinical profile and outcomes of primary percutaneous coronary intervention in young patients.

21. Batra MK, Rizvi NH, Sial JA, SaghirT, Karim M.Angiographic characteristics and in hospital outcome of young patients, age up to 40 versus more than 40 years undergoing primary percutaneous coronary intervention. J Pak Med Assoc. 2019 Sep;69(9):1308-1312. PMID: 31511716.

22. Xavier D, Pais P, Devereaux PJ, et al. Treatment and outcomes of acute coronary syndromes in India (CREATE): a prospective analysis of registry data. The Lancet. $2008 \mathrm{Apr}$ 26;371(9622):1435-42. https://doi.org/10.1016/S01406736(08)60623-6 26.

23. Kolte D, Khera S, Aronow WS, Mujib M, Palaniswamy C, Sule S, Jain D, Gotsis W, Ahmed A, Frishman WH, Fonarow GC. Trends in incidence, management, and outcomes of cardiogenic shock complicating ST凶elevation myocardial infarction in the United States. J Am Heart Assoc. 2014; 3:e000590. DOI: 10.1161/JAHA.113.000590. 